\title{
"Nonsense Rides Piggyback on Sensible Things": The Past, Present, and Future of Graphology
}

\section{Deborah Ellen Thorpe}

\begin{abstract}
"Nonsense rides piggyback on sensible things", declares professional sceptic and questioned-document analyst Joe Nickell in his chapter of The Write Stuff (1992: 15). ${ }^{1}$ Nickell refers to graphology's influence despite its failure to pass scientific validity tests. According to the British Institute of Graphologists (2015), graphology is the study of the "movement, spacing, and form" of handwriting. Handwriting presents both individual difference and internal variability, and practising graphologists use these variations to support statements about an individual's personality, mental health, and emotional state. Nickell's scathing metaphor expresses his qualms with the way in which graphologists exploit the wealth of information contained in handwriting to justify dubious assertions.
\end{abstract}

The original version of this chapter was revised. An erratum to this chapter can be found at https://doi.org/10.1007/978-3-319-73426-2_11

D. E. Thorpe $(\bowtie)$

Trinity Long Room Hub Arts and Humanities Research Institute, Trinity College Dublin, Dublin, Ireland

(C) The Author(s) 2018

H. C. Tweed, D. G. Scott (eds.), Medical Paratexts from Medieval to Modern, Palgrave Studies in Literature, Science and Medicine, https://doi.org/10.1007/978-3-319-73426-2_9 
Several well-respected applications of handwriting analysis scrutinize variations between, and within, scripts. For instance, questioned-document analysis in forensics examines handwriting features to detect forged signatures, identifies alterations in documents, and recognizes the author of anonymous script (Nickell 1992: 43). Palaeographers-researchers of the forms and processes of historical writing - might base an identification of an anonymous scribe on the most unconscious features of writing. Good practitioners in these fields are willing to admit the limitations of their methodologies without detracting from their overall validity. For instance, a palaeographer might advise that scribal hands vary on a day-to-day, or even an hour-to-hour, basis, which makes definitive identifications difficult.

In contrast, graphology is unique in its claims to be able to recover "the elusive quality of a writer's personality" from handwriting alone, without - as Nickell argues — standing up to rigorous academic examination. In addition, graphologists have been reluctant to admit their failures or define and justify their methodologies, likely due to a combination of professional competition, protectiveness of their reputation, awareness of the sceptical viewpoint of academic researchers, and a belief that scientific testing "oversimplifies" their work (Lockowandt 1992: 94). Finally, they neglect what many researchers perceive as one of the most useful applications of handwriting analysis - for the objective assessment of the movement disorders caused by different neurological conditions-choosing instead to focus on specious declarations about an individual's personality or character.

In a digital age, when it is possible to self-publish to diverse audiences through websites and social media, graphologists are finding louder voices online-as are the sceptics. Graphology is no longer restricted to the "occult sections of local libraries" as it was in the 1990s, but is easily discoverable on the internet (Beyerstein and Beyerstein 1992: 15). A search for "\#graphology" on Twitter returns copious tweets by and about graphologists, indicating that it is the subject of lively discussion online. The topic of graphology has been investigated by many online magazines and news outlets in recent years. Coverage ranges from light-hearted curiosity, as in The Guardian's piece "Prince Charles letters: What does a graphologist make of them?" (Khaleeli 2015), to ridicule in The Spectator blog's response: “Charles's 'spider letters': The Guardian falls for the pseudoscience of graphology" (Thompson 2015).

The handwritten letters of infamous criminals are particularly enticing to journalists, since they can be analysed retrospectively for clues that the crime was inevitable. Thus, graphologists are routinely ushered into the 
limelight to speculate about the mental health and criminal proclivities of certain writers. For instance, in 2016, the Daily Mail interviewed graphologist Brigitte Applegarth about letters written by the murderer of Labour MP Jo Cox: "[his] handwriting shows he has an inferiority complex and wishes to punish those who do not agree with him, according to an expert" (Greenwood and Sinmaz 2016). Whether positive or negative, these articles about graphology have increased its reach to public audiences. With this in consideration, I investigate whether graphology-the interpretation of handwriting as a paratext containing clues about the writer's personality-has gained any perceived legitimacy from its new visibility.

Touching on medicine specifically, I first ask: is it possible to metaphorically "dissect" the page of handwritten texts, to scrutinize writing as a "medical paratext" rich in information about the writer's state of health? Medical research suggests that it is: neurologists and psychiatrists are advancing investigations into the relationship between handwriting performance and brain activity. Studies have used writing as a tool for medical diagnosis, finding certain handwriting features to be reliable biomarkers for conditions such as Parkinson's disease (Rosenblum et al. 2013a). The effect of age-related deterioration on writing processes is also well documented, with handwriting changes being symptomatic of deterioration in the frontal and prefrontal cortex (Rosenblum et al. 2013b). Thus, there are uncomfortable synergies between graphology and medical handwriting assessment, both of which make connections between human differences and individual difference in handwriting. However, though the connection between medical pathology and handwriting performance is widely accepted, the relationship between psychological traits and states and writing is controversial. Despite this, even graphology's most vocal sceptics acknowledge that it is possible to learn something about a person, aside from their physical health, from their handwriting: clues about their gender, nationality, and profession, for instance (Nickell 1992: 46).

It is unsurprising, given its reputation as pseudoscience, that medical practitioners endeavour to sever any links with graphology. However, more surprising perhaps is that graphologists themselves have distanced themselves from medical diagnosis. For instance, graphologist James Crumbaugh (1992) has stated that "neither mental nor physical disease can be diagnosed by Graphoanalysis, but handwriting often provides information that helps the physician make a better estimate of the cause of the symptoms" (Crumbaugh 1992: 177). Taking an unusually cautious stance for a graphologist, Crumbaugh argues that an analysis of handwriting 
distortions can contribute to, but not determine, a medical diagnosis. This caution is uncharacteristic of a discipline that otherwise makes sweeping statements based upon handwriting features alone: for example, "[Prince Charles' writing is ] a nice clear hand, going logically forward,' [Graphologist Elaine Quigley says], which shows 'he is very much a man who likes to do things his own way"” (Khaleeli 2015).

It is possible that Crumbaugh's position is attributable to fear of his largely intuitive practice being undermined by empirical medical evidence. If so, this highlights a gap in the existing research: we need to know more about the nature of the connection between physical and mental states and handwriting. In fact, the boundary between "physical" and "mental" states, itself, is not clear, since there is currently active discussion among neurologists about what comprises a "psychiatric" disorder versus a "neurological" disorder-with some that have been previously labelled "disorders of the mind" being recently re-classified as having possible organic causation (Newby et al. 2017). Thus, the final section of this chapter demonstrates how academics are finally moving to fill this gap, going "back to basics" with their inquiries into individual difference and handwriting features.

This chapter is an updated study of graphology, providing a wider understanding of the concept of the paratext by considering the information captured in handwriting in the context of a digital age. It builds upon Barry and Dale Beyerstein's The Write Stuff (1992) to push the evaluation of this controversial, but well-known, discipline into the twenty-first century. There is a tendency to ignore graphology, to assign it to the past as "consigned to the dustbin of history" along with phrenology and astrology (Douglas 2015). However, the synergies and potential overlaps with other types of handwriting analysis should encourage us to make a more constructive criticism of graphology and its impact. Therefore, this chapter outlines the controversies and continuing allure of graphology in the twenty-first century, inspects the tangle between the types of handwriting analysis, and considers whether the idea of a connection between handwriting and subjective aspects of identity (such as psychological character) should be rejected entirely.

\section{Graphology, Its Controversies, and Allure, In The Twenty-First Century}

Graphology retained some popular appeal at the close of the last century, despite the lack of experimental support for its principles, and disputes about its validity prompted the publication of The Write Stuff in 1992, claiming in its blurb to give "a balanced evaluation" of the practice. 
However, the dawn of the twenty-first century brought louder sceptical voices, as regulators realized that graphology was a potential means of unlawful discrimination. The use of graphology in employee selection and monitoring by some companies led the Chartered Institute of Personnel and Development (CIPD) to state that "graphology does not provide a sufficient basis on which to make important decisions about selection, developmental potential, redundancy or aptitude for training" (1998/2001; Bradley 2005b).

In 2005, marketing expert Nigel Bradley expressed his anxiety that this condemnation of graphology, and the embarrassment of companies using it, might lead to its demise- "it runs the risk of becoming a knowledge which is 'lost' knowledge". Worse, he argued that critics had begun to avoid the topic entirely: there had been "an increase in the number of people who do not express an opinion on graphology" (Bradley 2005b). Consequently, students did not choose to study graphology, instead going for "'safer' subjects that are well known to prospective employers". Seeking to regulate graphology and recover its image, Bradley devised a "Code of Conduct for Graphology in Europe" (Bradley 2005a). Amongst his suggestions, which encouraged graphologists to offer an ethical and transparent service, he recommended a disconnect from what he sees as disreputable areas, such as "the occult" ("hypnosis, astrology, mediums, telepathy, and the paranormal"). As a result of graphology's association with the supernatural, he argued, it was considered "a popular toy that has no place in academia or the world of work". In a presentation given to graphologists in 2002, Bradley investigated the relationship between graphology and academia, concluding that "graphology needs to be present in academia ... to develop ... and to be accepted as a legitimate tool".

In preparing The Write Stuff, editor Barry Beyerstein undertook a search for such academic representation; he looked for "any independent support for graphological claims in the scientific literature" (Beyerstein and Beyerstein 1992: 15). He was unsuccessful, and instead was "forced to rely on garage sales, New Age booksellers, self-published tracts by graphologists themselves, and the occult sections of local libraries to find the majority of pro-graphology works" (Beyerstein and Beyerstein 1992: 15). If he were undertaking this task today, his search would be faster: the internet proliferates with guides to graphology; institutional pages for graphology organizations; pro-graphology articles (in the popular press and, more rarely, in academic journals); and the professional webpages of practising graphologists. 
However, the democratic nature of internet content also amplifies the controversies surrounding graphology. For instance, Wikipedia, being a collaborative encyclopedia that is subject to constant change, creates its own paratexts, by recording alterations to each article in its "article history" (see "How to Read an Article History" 2015). Its "Graphology" article allows unrivalled insight into modern critical responses to the practice, since it registers who has worked on, and who has contended, information in the article (2017, last edit May 6$)$. Treated as a primary text, this Wikipedia article and its paratext offer an opportunity to look over the shoulders of its readers and editors, many of them lay or nonspecialist (or, at least they do not claim relevant qualifications) as they engage with the definition of, history of, and potential future of graphology. For instance, user “Tronvillain” (three edits on 12 November 2016), who describes themself as having a bachelor's degree in biochemistry, makes amendments to the article's section on the history of graphology ("User:Tronvillain" 2016). Another non-specialist editor visible in the article's paratext is user "Geeveraune" who provides regular minor edits to the article on graphology in October and November 2016, but otherwise edits articles on geographic information system (GIS) software, historical battles, and places in Ireland ("User: Geeveraune" 2016).

As might be expected, the "Graphology" article is highly unstableamended regularly by both graphology supporters and sceptics. In the period July to September 2015, it received 27 edits, only six of which were classified "minor". The most frequent reasons for these were disputes over how to evaluate the practice. Most edits propose contrasting critiques of the practice, with graphology supporters and sceptics editing head-to-head. Tagged reasons for edits include "non neutral change", "not interesting biased", and studies being "not recent".

Many of the quickly-reverted edits are non-neutral, unsupported by evidence, and expressed in ungrammatical English. For instance, on 1 June 2015, “Dr Raghvendra Kumar” contributed the following change:

"Graphology' is the much more advance science than psychology and psy-
chiatry ... based on involuntary expression that is handwriting rather than
voluntary expression which is opinion which can not be true because of infinite
factors like ego, understanding, motive, circumstances, state of mind and so
on." Within just three minutes, the user "McSly" had revised the article, delet-
ing the new content, re-inserting the word "pseudoscientific", and adding the
reason "non neutral change". These edits display active policing of the article
by numerous individuals, resulting in a consensus on graphology. The article's 
current version upholds the sceptical perspective: "Graphology is the analysis of the physical characteristics and patterns of handwriting purporting to be able to identify the writer, indicating psychological state at the time of writing, or evaluating personality characteristics. It is generally considered a pseudoscience."

Though Wikipedia is not intended to be the sole source of reliable information, its dynamic, democratic, and accessible quality makes it a useful gauge of popular opinion-it is a "common resource of human knowledge" ("General Disclaimer" 2015). Internet users seeking an overview of graphology in 2018 will gain an overwhelmingly sceptical perspective from its Wikipedia entry, as its authors parade a series of pejorative adjectives: "worthless", "negative", "illegal", and "vague". However, the persistent allure of graphology should prompt us to ask the question: what can we learn about personality from handwriting, if anything? How does writing perform as a paratext, in relation to the meanings and contents of the words and phrases themselves? Is it possible to salvage the foundational principle of the practice of graphology: that there is some connection between handwriting features and the more subjective elements of human identity?

\section{“The Careless Flourish": What Can We Learn About Individual DifFERENCE From Handwriting?}

Handwriting has long provoked affective reading. In the Middle Ages, though even intimate letters were often written by scribes, autograph writing was occasionally used as a symbol of affection (Williams 2001: 213). Bernard of Clairvaux closed a letter with the autograph postscript: "I dictated these things but wanted you to recognize my love by a handwriting known to you" (Ganz 1999: 284; Williams 2001: 213). A member of the fifteenth-century Oxfordshire gentry, Elizabeth Stonor, used autograph postscripts - executed with considerable effort in her unpractised handto communicate personal news to her husband (Thorpe 2015: 87). For early modern correspondents, autography became more widespread, as a way of ensuring authenticity and representing the true will of the signatory, and so became a symbol of security, intimacy, and trust (Williams 2001: 225). This new prominence of autograph writing enabled writers to capture, and the reader to find, an element of their identity in the handwritten word-something that evades both the writing of an amanuensis and the orally-delivered message of a letter bearer (Williams 2001: 69). 
In our current age, where more and more information is recorded digitally, we are nostalgically captivated by handwriting. Though we write by hand increasingly rarely, the handwritten text holds special significance due to the uniqueness of its form. Artist Tim Murray-Browne, discussing his 2016 show "Movement Alphabet", has argued that this is because "handwritten text communicates character and mood"-it is the "residue" of a moving body, and thus the writing enables us to feel a connection with the person who wrote it. He describes an experience that is common to most of us - that of receiving a letter addressed with familiar handwriting: "I receive few handwritten envelopes in the post. I instantly recognize writing on the front for nearly all of them" (Murray-Browne 2016). Implicit in this statement is the emotional reaction provoked by recognition, for example, the joy of laying eyes on the handwriting of a beloved friend. This fascination with the individuality of handwriting has resulted in a proliferation of accounts of the discovery and subsequent curious - and sometimes highly emotional-investigation of handwritten letters and diaries by historical people.

Alexander Masters, in A Life Discarded (2016), recounts his compelling story of finding the diaries of an unknown woman, discarded in a skip. His article in The Guardian outlines the gradual process of discovery, as the unknown woman's identity becomes clearer, jointly through her handwriting features ("the measured way the writer records the date in blunt, soft pencil"), and the snippets of information and eventually a name"Laura"-that slowly emerge from the contents of the entries. As Masters learns more about Laura, he connects elements of her psychological state to her handwriting ("Laura's handwriting collapses with her spirit"), and he eventually employs two graphologists. One of these experts, the book reveals, tells him: "the person who has handwriting like this is a complete nutter", an unscientific and unhelpful response.

Despite this graphologist's frivolous inferences, Masters' emotional account highlights the evocative nature of handwriting, going some way to explaining the allure of graphology. In a 2014 lecture, historian Jane Caplan exemplified this persistent appeal by drawing attention to the inelegance of her own signature. Embracing the temptation to associate personality traits with handwriting features, she observed that her signature did not have "the careless flourish of writers who are so important or so busy that they have reduced their signature to a skeletal outline" (Caplan 2014). A connection between handwriting qualities and lifestyle is deeply ingrained in literate culture. For instance, conventional wisdom holds that 
doctors' handwriting is illegible. In fact, researchers have disagreed about whether this is true. Berwick and Winickoff (1996) state that the writing of doctors is comparable to non-medical executives, whereas Lyons et al. (1998) argue that it is demonstrably worse. The rumours are alarming due to the responsibilities that doctors have: we expect them to take care, and so are surprised by poor-quality writing in prescriptions and medical instructions. Psychologist Rowan Bayne reported to the BBC that graphology's magnetism is partially attributable to the unsophisticated information about personality that can be gleaned from handwriting: "[graphology is] very seductive because at a very crude level someone who is neat and well behaved tends to have neat handwriting" (see Duffy and Wilson 2005).

Caplan argues that although writing can be used for identification purposes, it also imparts more subjective ideas of identity. Whilst graphologists cannot claim, convincingly, the objectivity of forensic handwriting analysis, the branches of handwriting analysis "grow from the common tree" of human uniqueness (Caplan 2014). Each discipline engages with the "hand"; a word which "denotes simultaneously the part of our physical body that is most involved in the act of writing, the act of writing itself, and its results on paper" (Caplan 2014). Subjective and objective dimensions of identity are "separable, and yet entangled" in the word "hand" (Caplan 2014). So, I ask, should graphology's lack of credibility guide us to dismiss the more subjective applications of handwriting analysis? The sceptics imply that we should: Nickell distinguishes the work of a questioned-document examiner from that of the graphologist by stating that where the former addresses "a panoply of more or less objective problems", the latter attempts, and fails, to capture the "elusive quality" of a writer's personality (Nickell 1992: 43).

Studies have suggested that graphologists' inferences about these elusive qualities originate from the content of handwriting, rather than its form. The subject matter, vocabulary, or other linguistic features of the writing can transmit clues about the writer's personality or state of mind. This idea was proposed by Ben-Shakhar et al. (1986) and Neter and BenShakhar (1989), who argued that the perceived success of graphology might be due to graphologists' observations - conscious or unconsciousabout the content of the writing under analysis. We see this in action in $A$ Life Discarded, as Masters - unconsciously, or perhaps consciously for dramatic purposes - connects Laura's handwriting features with the personality traits and life events that slowly become clear from the diaries' content. 
Psychologists Roy King and Derek Koehler (2000) proposed that this effect is not limited to the content of words, but is also ingrained in the descriptive terminology that graphologists used to describe writing. They investigated a phenomenon known as "illusory correlation" as a contributor to graphology's persistent use to predict personality. In asking participants unfamiliar with graphology to match handwriting with personality profiles, King and Koehler found that "semantic association between words used to describe handwriting features and personality traits was the source of bias in perceived correlation" (King and Koehler 2000: 336).

However, I argue that we do not need to reject entirely the rationale behind graphology — that handwriting features might somehow reflect the more subjective elements of identity - due to the problems inherent in its conventional practice: this risks "throwing the baby out with the bathwater". Thus, I move on to demonstrate how promising research is reconfiguring the investigation into the link between handwriting features and individual psychological difference.

\section{Goodbye to "Graphology”? Reconfiguring the Study of Handwriting Features and Individual Difference}

Conventional graphology takes handwriting in isolation, making assertions about the writer's personality based on its features. Its failures arise partially from this approach: any information gleaned from the content of the writing is deemed "cheating". The focus on static features (for instance, the slant of the letters in a single writing sample) eliminate the context of a human life, with its fluctuating psychological, physical, and environmental states. Graphologists have not succeeded in providing significant experimental evidence to demonstrate the link between handwriting features and personality. Academics have not moved to fill this gap; the negative reputation of graphology has discouraged researchers from scientific research in this area. Finally, conventional practice has lacked a comparative element; it has not considered each handwriting sample within the context of a substantial data set.

Digital handwriting recognition is a thriving area of research, and computer scientists have been tempted to apply their methodologies to problems in the under-researched field of graphology. However, digital techniques such as handwriting feature extraction algorithms are tools, and act according to the imperatives of human researchers. Past studies 
that extract handwriting features and map them to personality traits have struggled to provide convincing evidence for the principles of graphology. They have either employed dubious approaches or provided little to no explanation of their own empirical methodologies (see Górska and Janicki 2012; Gawda 2014; Champa and Kumar 2010, 2011). Despite their failures, these studies illustrate graphology's attractiveness and increasing visibility, even within academic communities. This has been intensified by the proliferation of journals in each subject area, and the increasing availability of open access research online.

More recent, more successful, studies have elected to shed the term "graphology", producing robust, peer-reviewed studies that cautiously investigate writing features that might correspond with the more subjective aspects of identity. For instance, Miguel-Hurtado et al. (2014) combine expertise from psychology and electronics to identify both static and dynamic features in signatures as potential indicators of personality. Explicitly rejecting conventional graphology and adding the further criticism that it ignores the dynamic features of writing (such as writing velocity), they perform a closer scrutiny of how, and which, handwriting features should be measured. In line with previous studies into gender and handwriting, the study finds a connection between gender and writing: "sex classification" and "weight" could be predicted using signature features, especially velocity (see Beech and Mackintosh 2005). However, it also identifies a number of significant correlations between both dynamic and static features and personality features, particularly "conscientiousness" and "perseverance". 2

Other researchers are shifting the focus away from personality "traits" and towards changeable "states", such as emotions, stress level, and other psychological or psychiatric states. As far back as the 1970s, psychiatrists were interested in handwriting for insight into states of mental health. In 1971, renowned eating disorders specialist Pierre Beumont revealed that he had observed "peculiarities" in the handwriting of patients with anorexia nervosa. Providing illustrative figures, Beumont describes the "extremely small and neat" handwriting of some patients, noting also that in one case a difference could be seen in a sample taken before the onset of the patient's anorexia.

Moving into 2015, Fairhurst, Erbilek, and Li began to quantify the "soft biometrics" of handwriting-information that it contains that is not known to be unique, but is "nevertheless characteristic of an individual"- 
with a focus on digital methodologies. Like graphologists, the researchers extract handwriting features to predict "soft" characteristics, but their focus on changeable states, such as levels of happiness, anxiety, or stress levels eradicates the rigidity of conventional graphology. Unlike the prographology articles discussed above, this new research cites studies that suggest that the prediction of emotions from handwriting is possible (Fairhurst et al. 2015; Mutalib et al. 2008). Shifting away from graphology's exclusively human inspection of handwriting, the preliminary study proposes a system for automatically predicting the emotional state of the writer from a handwriting sample.

In a range of pre-determined writing tasks, which were captured using a digitizing tablet with a paper overlay, Fairhurst, Erbilek, and Li found $57 \%$ accuracy in a "happy" prediction from the static features of the writing, and a $69.1 \%$ accuracy from the dynamic features. When three more features were added to the static feature set, this predictive accuracy increased further. The accuracy levels were less consistent, but not necessarily lower, in unconstrained tasks (where the writing data generated was under the control of the experimental subject). Despite only one sample per person being available in each task, making a longitudinal study impossible, these results are encouraging.

These optimistic studies recommend more in-depth explorations in the area of individual difference, psychological states, and handwriting. Fairhurst, Erbilek, and Li conclude by suggesting further research into the relationship between handwriting features and predictive capability. They propose an investigation into how we can establish ground truth markers for the historical context of emotion, i.e. how do we indicate, reliably, whether a writer was "happy" or otherwise at the time of writing? Finally, they recognize the need to gather more handwriting data to investigate the predictive capability of writing more thoroughly. Importantly, these exploratory studies succeed where the older prographology articles have failed-in avoiding sweeping statements about writing and personality in the absence of convincing evidence about the nature of the link. Instead, the authors display cautious optimism, finally supported by rigorous research. Miguel-Hurtado et al. (2014) suggest that this kind of work could have practical applications in forensics. In the case of a criminal investigation where an offender has left behind handwritten evidence, confident predictions about the person's personality based on his or her writing, could lead to a more targeted search. 


\section{Conclusion}

Unlike phrenology and astrology, which have been consigned to the past as defunct practices, graphology retains popular appeal. Handwriting continues to be seen as a paratextual puzzle waiting to be solved, rich in information about the writer's personality. Moreover, in contrast with the 1990s, when Beyerstein and Beyerstein researched The Write Stuff, graphology has extended onto the internet and, to a limited extent, into the methodologies of academic research. Graphology is no longer consigned to "the occult section of local libraries" (Beyerstein and Beyerstein 1992: 15), but instead proliferates on the internet and in the mainstream media, and thus psychologists should continue to investigate its claims. As Nickell explained, "Nonsense rides piggyback on sensible things." Academic research into the validity of the claims of graphologists continues to report against them: there is "no evidence ... to validate the graphological method as a measure of personality" (Dazzi and Pedrabissi 2009).

However, the appeal of graphology — or its foundational idea that individual psychological difference is somehow reflected in handwriting-is itself significant. As Jane Caplan (2014) has shown, the word "hand", as in the phrase "scribal hand", incorporates both objective and subjective concepts of identity. The more that society values individuality, the more alluring becomes the idea that handwriting features are personal, and thus meaningful (Thornton 1998: 140), and, thus, the more we are tempted to investigate the links between handwriting and personality. Furthermore, recent scholarship, distancing itself from conventional graphology, and its sweeping and unsupported statements about personality, is going "back to basics" in the investigation into individual difference and handwriting. With a new focus on rigorous experimental methodologies, significant and representative datasets, and careful peer review, preliminary investigations are optimistic about the link between handwriting features and "soft" biometrics - that is, traits and states that are characteristic of an individual.

\section{Notes}

1. For previous brief discussions of graphology in the context of psychiatric health, see Schiegg and Thorpe (2016), which otherwise focuses on the ways in which handwriting analysis has been used in psychiatric assessment in the early twentieth century (1-24).

2. As measured on the UPPS impulsivity scale (see Whiteside and Lynam 2001.) 


\section{BIBLIOGRAPHY}

Beech, John R., and Isla C. Mackintosh. 2005. Do Differences in Sex Hormones Affect Handwriting Style? Evidence from Digit Ratio and Sex Role Identity as Determinants of the Sex of Handwriting. Personality and Individual Differences 39 (2): 459-468. https://doi.org/10.1016/j.paid.2005.01.024.

Ben-Shakhar, Gershon, Maya Bar-Hillel, Yoram Bilu, Edor Ben-Abba, and Anat Flug. 1986. Can Graphology Predict Occupational Success? Two Empirical Studies and Some Methodological Ruminations. Journal of Applied Psychology 71: 645-653. https://doi.org/10.1037/0021-9010.71.4.645.

Berwick, Donald M., and David E. Winickoff. 1996. The truth about doctors' handwriting: A prospective study. BMJ 313 (7072): 1657-1658.

Beumont, Pierre. 1971. Small Handwriting in Some Patients with Anorexia Nervosa. The British Journal of Psychiatry 119: 349-351. https://doi. org/10.1192/bjp.119.550.349-a. Accessed Jan 2016. Accessed 8 Jan 2015.

Beyerstein, Barry L., and Dale F. Beyerstein. 1992. General Introduction to The Write Stuff: Evaluations of Graphology, the Study of Handwriting Analysis, ed. Barry L. Beyerstein and Dale F. Beyerstein, 13-22. Buffalo: Prometheus Books. Bradley, Nigel. 2005a. Codes of Conduct and Graphology. Paper Presented at the 8th British Symposium of Graphology Proceedings, St. Anne's College, Oxford. http://www.wmin.ac.uk/marketingresearch/graphology/ethicsoxford05eng.htm

- 2005b. Users of Graphology. Graphology, the Journal of the British Academy of Graphology 69: 55-57.

British Institute of Graphologists. 2015. What Is Graphology? http://www.britishgraphology.org/about-british-institute-of-graphologists/what-is-graphology/. Accessed 8 Jan 2015.

Caplan, Jane. 2014. Your Hand: Signatures and Writing. Lecture Presented at Gresham College, London, June 23. http://www.gresham.ac.uk/lecturesand-events/your-hand-signatures-and-handwriting.

Champa, H. N., and K. R. Ananda Kumar. 2010. Automated Human Behavior Prediction Through Handwriting Analysis. Paper Presented at the 2010 First International Conference on Integrated Intelligent Computing (ICIIC), Bangalore, August 5-6, 2010. doi:https://doi.org/10.1109/ICIIC.2010.29.

Champa, H.N., and K.R. Ananda Kumar. 2011. Rule-Based Approach for Personality Prediction Through Handwriting Analysis. International Journal of Computational Intelligence and Healthcare Informatics 4: 27-29.

Chartered Institute for Personnel and Development. 1998/2001. Graphology: Quick Facts. London: CIPD.

Crumbaugh, James. 1992. Graphoanalytic Clues. In The Write Stuff: Evaluations of Graphology, the Study of Handwriting Analysis, ed. Barry L. Beyerstein and Dale F. Beyerstein, 105-120. Buffalo: Prometheus Books. 
Dazzi, Carla, and Luigi Pedrabissi. 2009. Graphology and Personality: An Empirical Study on Validity of Handwriting Analysis. Psychological Reports 105: 1255-1268. https://doi.org/10.2466/PR0.105.F.1255-1268.

Douglas, Ian. 2015. Male and Female Brains Are Utter Tosh-Yet We Still Have Men and Women. The Telegraph, December 2. http://www.telegraph.co.uk/ women/life/male-and-female-brains-are-utter-tosh---yet-we-still-havemen-an/. Accessed 5 June 2017.

Duffy, Jonathan, and Giles Wilson. 2005. Writing Wrongs. BBC News Magazine, February 1. http://news.bbc.co.uk/1/hi/magazine/4223445.stm. Accessed 5 June 2017.

Fairhurst, Michael, Meryem Erbilek, and Cheng Li. 2015. Study of Automatic Prediction of Emotion from Handwriting Samples. IET Biometrics 4: 90-97. https://doi.org/10.1049/iet-bmt.2014.0097.

Ganz, David. 1999. 'Mind in Character': Ancient and Medieval Ideas About the Status of the Autograph as an Expression of Personality. In Of the Making of Books: Medieval Manuscripts, Their Scribes and Readers. Essays Presented to M B. Parkes, ed. P.R. Robinson and Rivkah Zim, 280-299. Aldershot: Scolar.

Gawda, Barbara. 2014. Lack of Evidence for the Assessment of Personality Traits Using Handwriting Analysis. Polish Psychological Bulletin 45: 73-79. https:// doi.org/10.2478/ppb-2014-0011.

"General Disclaimer." 2015. Wikipedia, The Free Encyclopedia. Last Modified December 17, 2015. https://en.wikipedia.org/wiki/Wikipedia:General_ disclaimer

Górska, Zuzanna, and Artur Janicki. 2012. Recognition of Extraversion Level Based on Handwriting and Support Vector Machines. Perceptual \& Motor Skills 114: 857-869. https://doi.org/10.2466/03.09.28.PMS.114.3.857-869.

"Graphology." Wikipedia, The Free Encyclopedia. Last Modified May 6, 2017. https://en.wikipedia.org/wiki/Graphology

Greenwood, Chris, and Emine Sinmaz. 2016. Jo Cox's Killer Warned of 'Bloody Struggle' for White Supremacy and Even Signed Off Letters to Pro-apartheid Magazine with 'Racial Regards.' http://www.dailymail.co.uk/news/article-3969826/Jo-Cox-s-killer-warned-bloody-struggle-white-supremacysigned-letters-pro-apartheid-magazine-racial-regards.html\#ixzz4hQGoSmK3. Accessed 5 June 2017.

"How to Read an Article History." 2015. Wikipedia, The Free Encyclopedia. Last Modified May 23, 2017. http://en.wikipedia.org/wiki/Wikipedia:How_ to_read_an_article_history

Khaleeli, Homa. 2015. Prince Charles Letters: What Does a Graphologist Make of Them? The Guardian, March 29. http://www.theguardian.com/uknews/shortcuts/2015/mar/29/prince-charles-letters-graphologist. Accessed 5 June 2017. 
King, Roy N., and Derek J. Koehler. 2000. Illusory Correlations in Graphological Inference. Journal of Experimental Psychology: Applied 6: 336-348. https:// doi.org/10.1037/1076-898X.6.4.336.

Lockowandt, Oskar. 1992. The Present Status of Research on Handwriting Psychology as a Diagnostic Method. In The Write Stuff. Evaluations of Graphology. The Study of Handwriting Analysis, ed. Barry L. Beyerstein and Dale F. Beyerstein, 55-85. Buffalo: Prometheus Books.

Lyons, Ronan, Christopher Payne, Michael McCabe, and Colin Fielder. 1998. Legibility of Doctors' Handwriting: Quantitative Comparative Study. BMJ 317: 863-864. https://doi.org/10.1136/bmj.317.7162.863.

Miguel-Hurtado, Oscar, Richard Guest, Sarah V. Stevenage, and Greg J. Neil. 2014. The Relationship Between Handwritten Signature Production and Personality Traits. Paper Presented at the International Joint Conference on Biometrics, Clearwater, September 29-October 2, 2014. https://doi. org/10.1109/BTAS.2014.6996245.

Murray-Browne, Tim. 2016. Foreign Scripts and Familiar Handwriting. Movement Alphabet, September 12. http://movementalphabet.com/foreign-scripts-andfamiliar-handwriting/. Accessed 5 June 2017.

Mutalib, Sofianita, Roslina Ramli, Shuzlina Abdul Rahman, Marina Yusoff, and Azlinah Mohamed. 2008. Towards Emotional Control Recognition Through Handwriting Using Fuzzy Inference. Paper Presented at the International Symposium on Information Technology, Kuala Lumpur, Malaysia, August 26-28, 2008. https://doi.org/10.1109/ITSIM.2008.4631735.

Neter, Efrat, and Gershon Ben-Shakhar. 1989. The Predictive Validity of Graphological Inferences: A Meta-Analytic Approach. Personality and Individual Differences 10: 737-745. https://doi.org/10.1016/01918869(89)90120-7.

Newby, Rachel E., Deborah E. Thorpe, Peter A. Kempster, and Jane E. Alty. 2017. A History of Dystonia: Ancient to Modern. Movement Disorders Clinical Practice 4: 1-8. https://doi.org/10.1002/mdc3.12493.

Nickell, Joe. 1992. A Brief History of Graphology. In The Write Stuff: Evaluations of Graphology, the Study of Handwriting Analysis, ed. Barry L. Beyerstein and Dale F. Beyerstein, 23-29. Buffalo: Prometheus Books.

Rosenblum, Sara, Batya Engel-Yeger, and Yael Fogel. 2013a. Age-Related Changes in Executive Control and Their Relationships with Activity Performance in Handwriting. Human Movement Science 32: 363-376. https://doi. org/10.1016/j.humov.2013.08.001.

Rosenblum, Sara, Margalit Samuel, Sharon Zlotnik, Ilana Erikh, and Ilana Schlesinger. 2013b. Handwriting as an Objective Tool for Parkinson's Disease Diagnosis. Journal of Neurology 260: 2357-2361. https://doi.org/10.1007/ s00415-013-6996-x. 
Schiegg, Markus, and Deborah Thorpe. 2016. Historical Analyses of Disordered Handwriting: Perspectives on Early 20th-Century Material from a German Psychiatric Hospital. Written Communication 34: 30-53. https://doi. org/10.1177/0741088316681988.

Thompson, Damian. 2015. Charles's 'Spider Letters': The Guardian Falls for the Pseudoscience of Graphology. The Spectator, May 13. https://blogs.spectator. co.uk $/ 2015 / 05 /$ charless-spider-letters-the-guardian-falls-for-the-pseudoscience-of-graphology/. Accessed 5 June 2017.

Thornton, Tamara Plakins. 1998. Handwriting in America: A Cultural History. New Haven/London: Yale University Press.

Thorpe, Deborah. 2015. 'I Haue Ben Crised and Besy': Illness and Resilience in the Fifteenth-Century Stonor Letters. The Mediaeval Journal 5: 85-108. https://doi.org/10.1484/J.TMJ.5.108526.

“User Contributions. For Geeveraune." 2016. Wikipedia, The Free Encyclopedia. https://en.wikipedia.org/wiki/Special:Contributions/Geeveraune. Accessed 5 June 2017.

"User:Tronvillain." 2016. Wikipedia, The Free Encyclopedia. Last Modified January 20, 2017. https://en.wikipedia.org/wiki/User:Tronvillain.

Whiteside, Stephen P., and Donald R. Lynam. 2001. The Five Factor Model and Impulsivity: Using a Structural Model of Personality to Understand Impulsivity. Personality and Individual Differences 30: 669-689. https://doi.org/ 10.1016/S0191-8869(00)00064-7.

Williams, Sarah Rhiannon. 2001. English Vernacular Letters c. 1400-1600: Language, Literacy and Culture. PhD Dissertation, University of York.

Open Access This chapter is licensed under the terms of the Creative Commons Attribution 4.0 International License (http://creativecommons.org/licenses/ by $/ 4.0 /$ ), which permits use, sharing, adaptation, distribution and reproduction in any medium or format, as long as you give appropriate credit to the original author(s) and the source, provide a link to the Creative Commons license and indicate if changes were made.

The images or other third party material in this chapter are included in the chapter's Creative Commons license, unless indicated otherwise in a credit line to the material. If material is not included in the chapter's Creative Commons license and your intended use is not permitted by statutory regulation or exceeds the permitted use, you will need to obtain permission directly from the copyright holder.

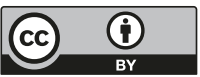

